\title{
Functioning Implant: The Term that Needs to be Defined
}

Pravinkumar G Patil

International Journal of Prosthodontics and Restorative Dentistry (2019): 10.5005/jp-journals-10019-1237

Implant dentistry is defined as the field of dentistry dealing with the diagnosis, surgical placement, prosthetic reconstruction, and maintenance of dental implants. ${ }^{1}$ On the background, every single effort is being made in the form of scientific development, research, and evidence; we are still not clear on what exactly we mean by a functioning implant in oral cavity; what are the criteria to claim a particular implant to be a functioning implant; and how the functioning implant, we expect, to behave. Although dental implants are proved to be a predictable longterm treatment for patients, it is important to realize that not all implants that survive are necessarily successful. ${ }^{2}$ Successful implants are those that remain fully functional and healthy within the oral cavity. ${ }^{2}$

The current version of the Glossary of Implant Dentistry (GID) III ${ }^{1}$ has defined many terms in this regard, including implant success, survival, and failure. Implant survival is defined as a longevity of a dental implant within the oral cavity. If we assume a particular implant is surviving in oral cavity but not in occlusion, then this may be considered as a non-functioning (or non-occluding) implant and not really considered as a functioning implant. Hence, there is a need to set clear guidelines or criteria or need to have an expert consensus to define the term functioning implant. Nonetheless, the term functional (or occlusal loading) has been defined as the restoration is in an occlusal contact with the opposing dentition in the maximal intercuspal position and/or excursions. ${ }^{1}$ Apart from mastication, the esthetics and speech also needs to be involved in the criteria to define the functioning implant. Crestal bone
Division of Clinical Dentistry, Department of Prosthodontics, School of Dentistry, International Medical University, Kuala Lumpur, Malaysia

Corresponding Author: Pravinkumar G Patil, Division of Clinical Dentistry, Department of Prosthodontics, School of Dentistry, International Medical University, Kuala Lumpur, Malaysia, Phone: +60 1135022042, e-mail: pravinandsmita@yahoo.co.in

How to cite this article: Patil PG. Functioning Implant: The Term that Needs to be Defined. Int J Prosthodont Restor Dent 2019;9(2):35.

Source of support: Nil

Conflict of interest: None

level change (which is a continuous phenomenon) is one of the important success indicator of the implant treatment. The more bone loss occurs around the implant/s, the less is the chance to remain the particular implant/s as a functioning unit in oral cavity in the long run. Multiple factors are responsible for the implant to remain as a functioning unit, and clinicians should be aware of its importance.

\section{References}

1. Glossary of Implant Dentistry III, International Congress of Oral Implantologists. Fairfield NJ: ICOI Inc.; 2017. pp. 8-143.

2. Clark D, Levin L. Dental implant management and maintenance: How to improve long-term implant success? Quintessence Int 2016;47(5):417-423. DOI: 10.3290/j.qi.a35870.

(c) The Author(s). 2019 Open Access This article is distributed under the terms of the Creative Commons Attribution 4.0 International License (https://creativecommons. org/licenses/by-nc/4.0/), which permits unrestricted use, distribution, and non-commercial reproduction in any medium, provided you give appropriate credit to the original author(s) and the source, provide a link to the Creative Commons license, and indicate if changes were made. The Creative Commons Public Domain Dedication waiver (http://creativecommons.org/publicdomain/zero/1.0/) applies to the data made available in this article, unless otherwise stated. 